
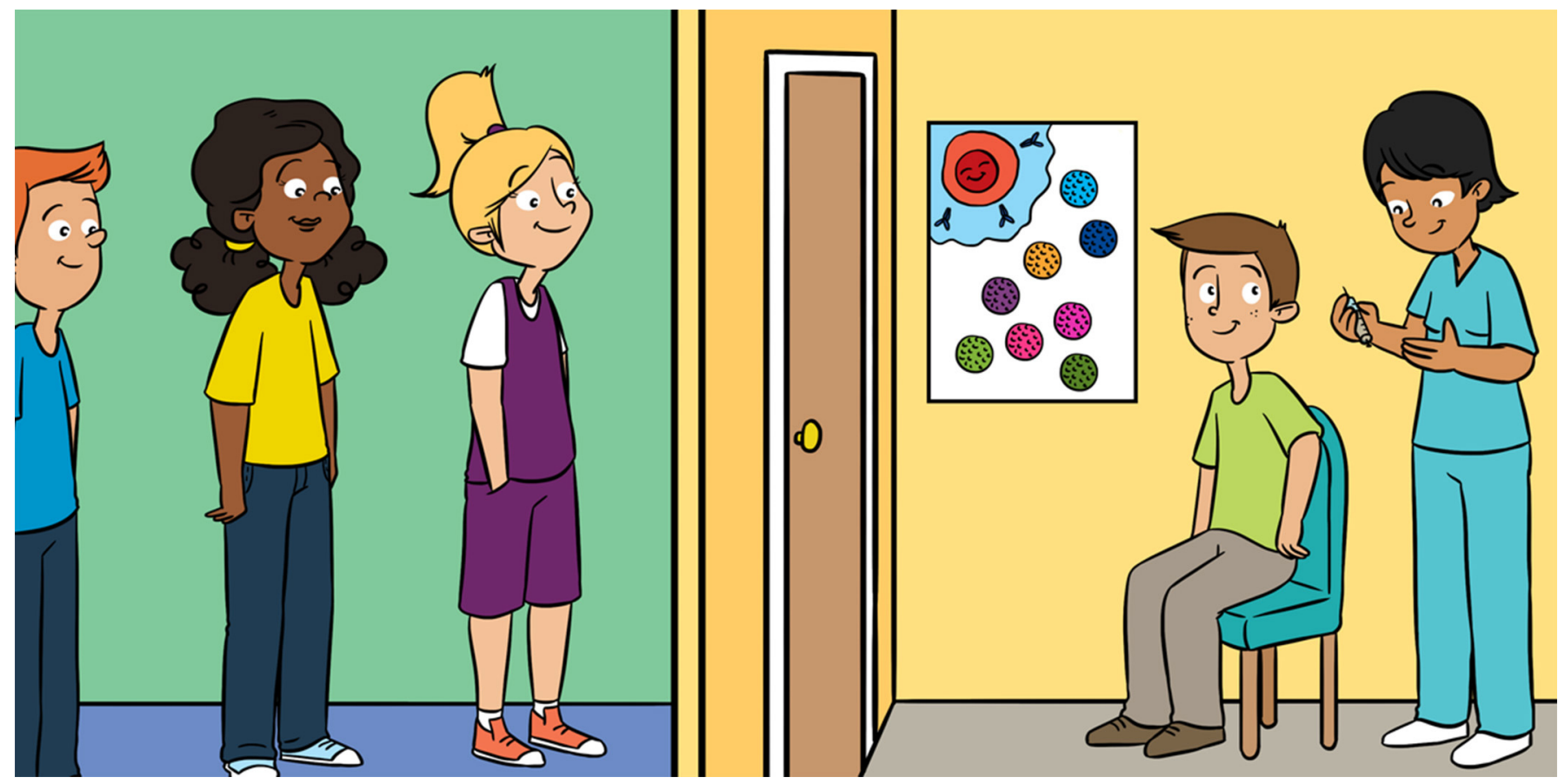

\title{
HUMAN PAPILLOMAVIRUS IS DANGEROUS-BUT A VACCINE CAN SAVE YOU!
}

\author{
Marie Neunez ${ }^{1,2^{*}}$, Susan Nasif ${ }^{3,4,5}$, Pierre R. Smeesters ${ }^{6,7,8,9}$ and Hilde Stevens ${ }^{1}$ \\ ${ }^{1}$ Institute for Interdisciplinary Innovation in healthcare (I3h), Université Libre de Bruxelles, Brussels, Belgium \\ ${ }^{2}$ The Belgian Kids' Fund for Pediatric Research, Brussels, Belgium \\ ${ }^{3}$ Doctoral School of Biomedical Sciences, KU Leuven, Leuven, Belgium \\ ${ }^{4}$ Cimaza Virology Comics, Brussels, Belgium \\ ${ }^{5}$ The Neyts-Lab of Virology, Antiviral Drug and Vaccine research, Katholieke Universiteit Leuven, Leuven, Belgium \\ ${ }^{6}$ Molecular Bacteriology Laboratory, Université Libre de Bruxelles, Brussels, Belgium \\ 7 Tropical Diseases Research Group, Murdoch Children's Research Institute, Melbourne, VIC, Australia \\ ${ }^{8}$ Department of Paediatrics, University of Melbourne, Melbourne, VIC, Australia \\ ${ }^{9}$ Academic Children Hospital Queen Fabiola, Université Libre de Bruxelles, Brussels, Belgium
}

YOUNG REVIEWERS:

A. Y. JACKSON

S.S.

(TORONTO DISTRICT SCHOOL BOARD) AGES: $13-15$
Human papilloma virus (HPV) is a virus that can cause disease in the skin and mucus membranes of both women and men. There are more than 100 types of HPV. While most of them cause harmless infections, some types of HPV are more harmful and can lead to cancers. HPV infection cannot be cured. The only solution is to prevent infection by vaccinating girls and boys at the age of 9-15. HPV vaccination prevents the infection and also stops the spread of the virus from one person to another. This article will help you to understand the basics about HPV, the diseases it causes, and why the HPV vaccine is an important solution. 
Figure 1

The structure of HPV. HPV is composed of proteins that assemble themselves into starry shield shapes.

Seventy-two Starry shields assemble to create the capsid, which encloses the viral DNA (illustrated by Susan Nasif).

\section{MUCOUS}

MEMBRANE

The tissue that lines the inside of numerous organs, including the oral cavity, the nasal cavity, and the genitals.

\section{CAPSID}

The protein structure that surrounds the genetic material of the virus, like a shell.

\section{MALIGNANT LESION}

An abnormal new growth of tissue/cells which usually develops rapidly and spreads to the whole body. It is life-threatening if it is not taken care of.

\section{WART}

An abnormal growth of cells, most frequently in the shape of a nipple or cauliflower.

\section{CONDYLOMA}

A wart located in the mucous membrane for example on the genitals or in the throat.
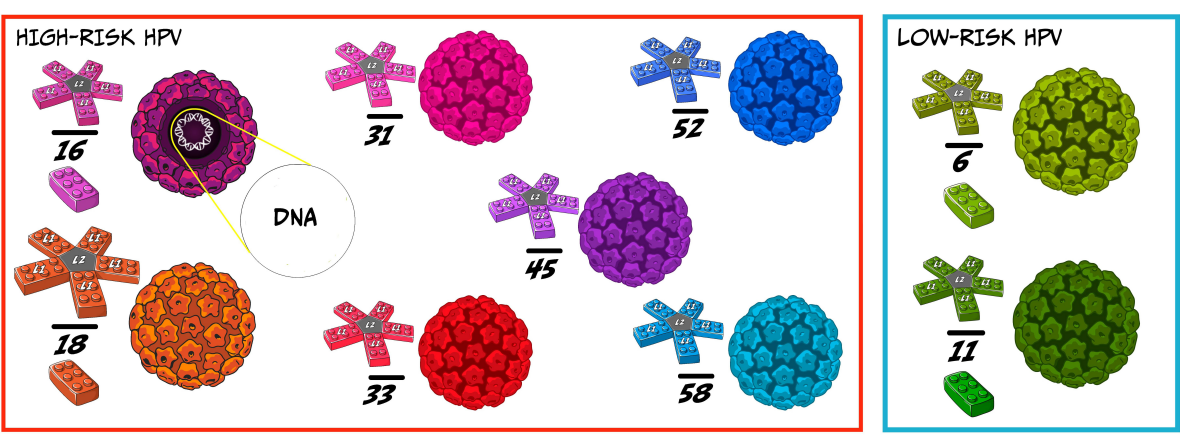

CAPSID PROTEIN , DIFFERENT FOR EACH TYPE OF HPV

Figure 1

\section{WHAT IS HUMAN PAPILLOMAVIRUS?}

The human papillomavirus, also known as HPV, is a virus that infects humans and causes "papilloma." The word papilloma is composed of "papilla," which means pimple, and "oma," which refers to an abnormal growth of cells, otherwise known as a tumor. HPV preferably infects cells of the skin and the mucous membranes. The skin is an organ, with several tissue layers, that forms the natural protective barrier of a person's body. Mucous membranes are the tissues that line the inside of numerous organs, such as the mouth, the throat, and the genitals.

Viruses are invisible to the naked eye, but they can be observed using a powerful microscope. HPV has a round shape, and its diameter is $55 \mathrm{~nm}(1 \mathrm{~nm}=0.0000001 \mathrm{~cm})$. This is a million times smaller than a tennis ball! Some of the proteins that make up HPV combine to form a star-shaped shield, kind of like a star built from Lego ${ }^{\circledR}$. In total, 72 starry shields assemble to create the round shape of HPV, which is called the capsid. The capsid contains the viral DNA (Figure 1) [1, 2].

\section{HPV COMES IN DIFFERENT FORMS AND SPREADS VIA DIFFERENT ROUTES}

HPV is not just one virus. There are more than 100 kinds of HPV, but most of them are rare and not dangerous. Each kind of HPV has a slightly different looking starry shield and therefore has unique characteristics. Scientists have given each type of HPV a number to identify it. Some types of HPV, like 16 and 18, are very harmful for humans (called high-risk HPV) and can cause malignant lesions, leading to cancers in various parts of the body. Others, like 6 and 11 , are less dangerous (called low-risk HPV) and might create wounds, such as warts or condyloma (Figure 2) [2]. Condylomas are warts that are located in the mucous membrane of the body, for example in the 
Figure 2

Lesions associated with HPV infection. Infection with some types of HPV can lead to benign conditions, such as warts or condylomas. Other HPV types are more dangerous and can cause malignant lesions, such as cancer of the uterus. The yellow triangle on the lower right image shows the evolution of the cervix cells from normal (top) to cancerous (bottom) cell formation (illustrated by Susan Nasif).

\section{BENIGN LESION}

An abnormal new growth of tissue/cells which develops slowly and remains local where it initially originates. It is not life-threatening, but sometimes it evolves toward malignancy.

\section{CERVIX}

The narrow outer end of the uterus, which is the main female reproductive organ.

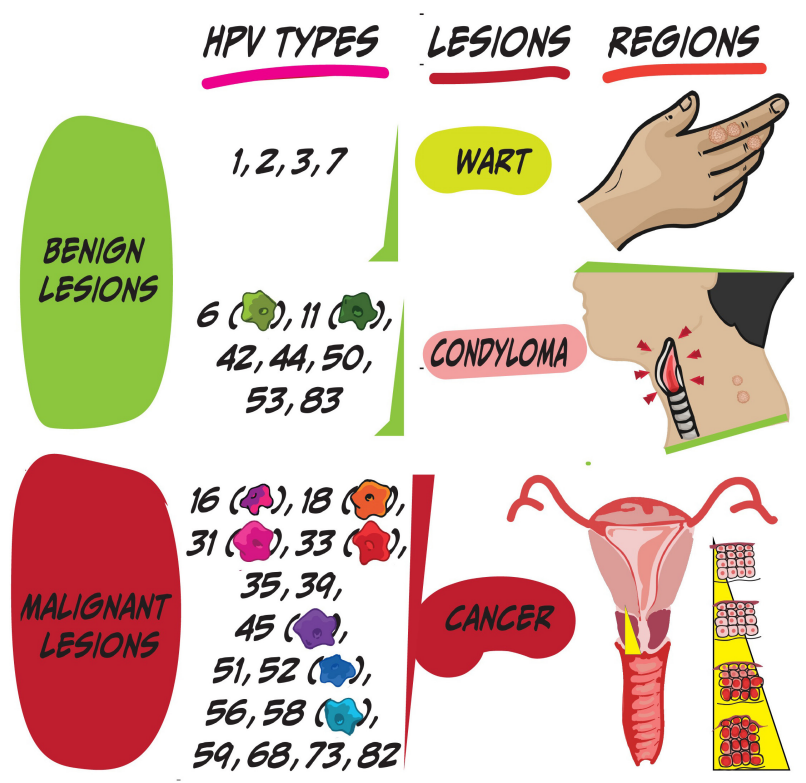

Figure 2

throat. Warts and condylomas are called benign lesions because they are not a threat to human lives.

It is estimated that the majority of adults worldwide are or have been infected by HPV. Most people do not even notice the infection, but can still infect other people. Infections can happen in swimming pools or through skin-skin contact when you shake hands. When a mother is infected, she can transmit the virus to her baby during childbirth. HPV is also the most common sexually transmitted disease and can be passed on through close intimacy and sexual contact.

\section{SYMPTOMS: FROM WARTS TO CANCER}

More than half of the types of HPV $(\sim 60)$ cause warts on the skin of various body regions, like hands and feet. Those lesions are usually not dangerous for human health. The other HPV types ( 40) enter the body during sexual contact and intimacy. Of these, types 6 and 11 cause condyloma. Condyloma is not life threatening. However, types 16 and 18 contribute to cervical cancer. The cervix is a part of the uterus, an essential female reproductive organ. Cervical cancer is one of the top killers of women in the world. The German physician-virologist Harald zur Hausen discovered the link between HPV and cervical cancer in 1983 [3]. In 2008, he won the Nobel Prize in Medicine for that discovery!

Although HPV infects women and men equally, women have the highest risk of developing cancer when they get infected by a high-risk type of HPV. Most cases of cervical cancer are caused by an HPV infection. Some oral and throat cancers can also be linked to HPV, and 
Figure 3

From HPV infection to cervical cancer. The blue square shows the infection of a cell by HPV. In the lower part of the drawing, you see the evolution of the cervix cells from normal (green) to cancerous (red) cell formation (illustrated by Susan Nasif).

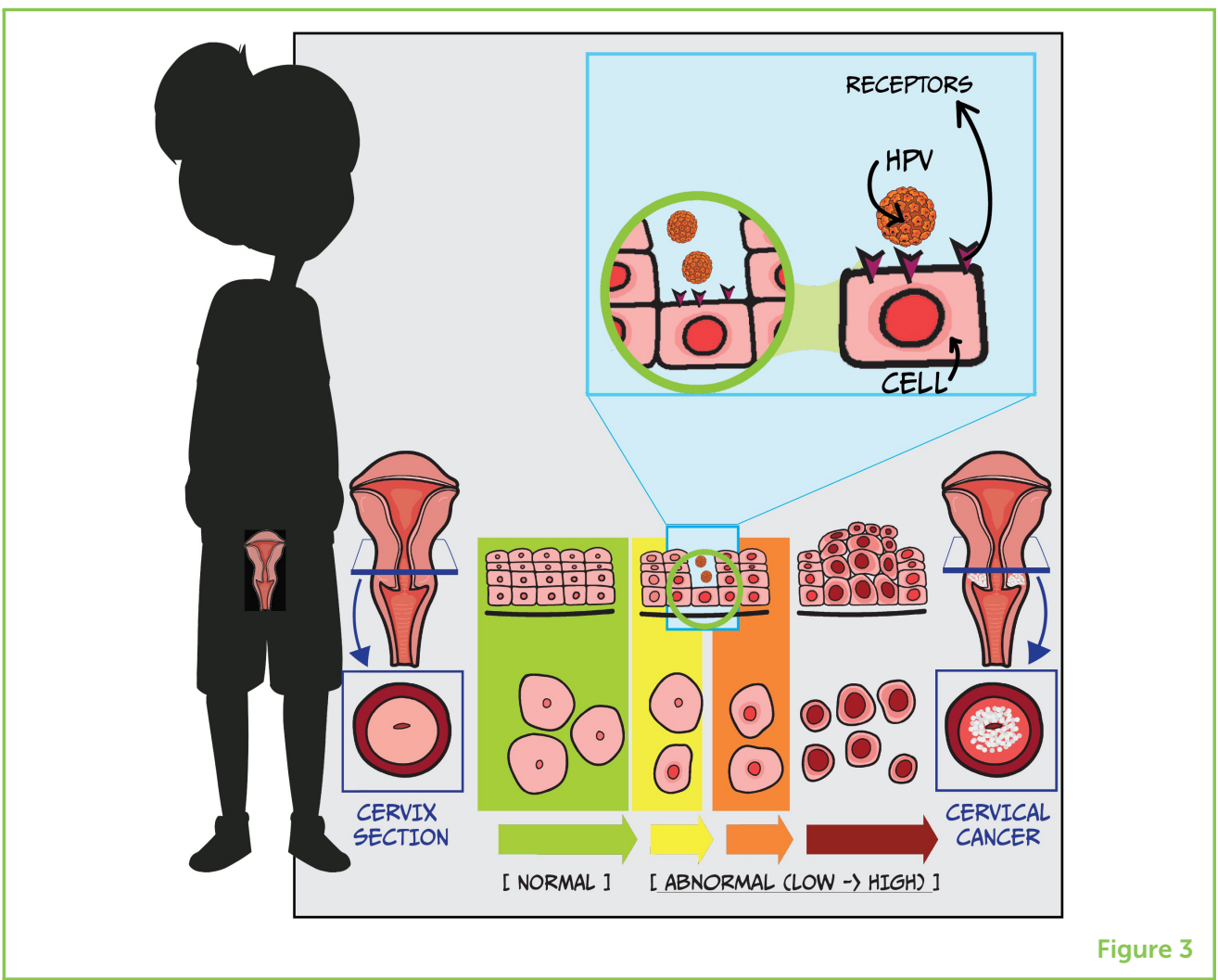

although these are less common than cervical cancer, it is important to remember that men are also vulnerable to HPV infection and can also develop cancer.

Being infected by HPV does not mean that a person will definitely develop a tumor. This is good news, because HPV infection is the most common viral infection of the reproductive tract. To develop cancer, a person must be infected by a high-risk type of HPV and be infected for a long time, meaning that the person's body is not able to fight against the virus effectively. To better understand the risks linked to HPV infection, if 10 adolescents are infected, 9 will clear the virus from their bodies and only 1 will develop a serious disease, such as cervical cancer.

Sometimes, when a high-risk type of HPV infects human cells, the virus can mislead the immune system and maintain its infection. This long-standing infection is the first step in the potential development of cancer. The infection starts at the deepest layer of the skin or mucous membranes (see yellow triangle in Figure 2). HPV disrupts the functioning of the cells it infects [1]. After taking control of the cells, HPV can reproduce itself and invade more cells, from the deepest layers to the surface. Each infected cell displays an abnormal appearance that doctors and scientists can detect if they examine the cells using a microscope (Figure 3). 
Figure 4

What is the HPV vaccine? Section 1 illustrates a cell being infected by HPV and turning sick. Section 2 illustrates the stages to create the vaccine against HPV, namely by using yeast cells to produce VLPs that mimic the appearance of HPV. Section 3 illustrates a cell being infected by HPV. The immune system of the cell fights efficiently the virus thanks to the vaccine previously received (illustrated by Susan Nasif).

\section{VIRUS-LIKE}

\section{PARTICLE}

Small particle that appears like a certain virus since it contains proteins from the viral capsid. They do not contain viral genetic material and can therefore not cause an infection. They are usually synthesized in laboratories to mimic a virus, like in the HPV vaccine.

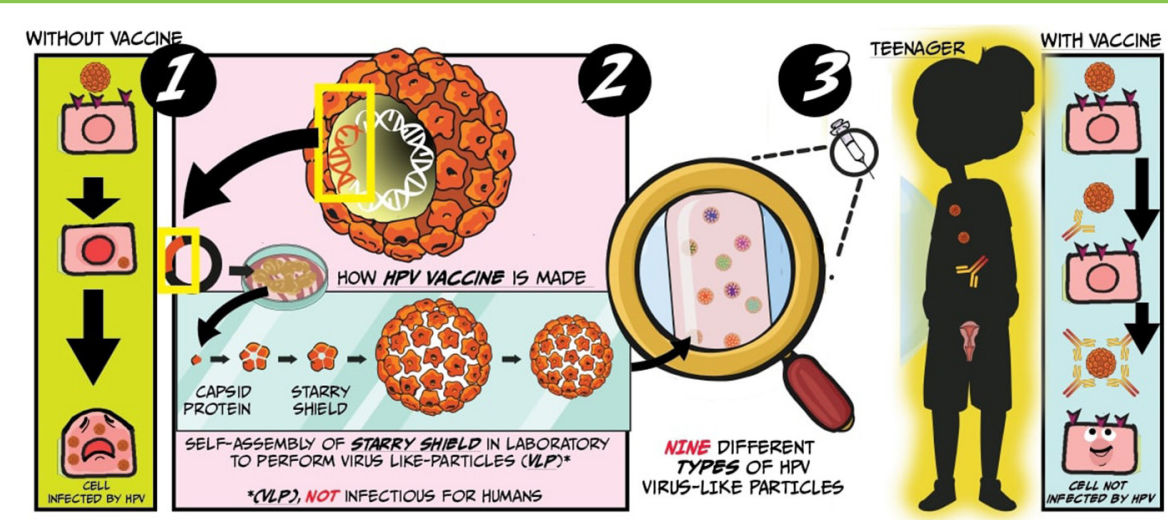

Figure 4

\section{VACCINATION KEEPS US PROTECTED FROM HPV}

HPV infection cannot be cured. The only solution is to prevent HPV infection from happening in the first place, through vaccination. Currently, the HPV vaccine can protect us against nine high-risk types of HPV: $6,11,16,18,31,33,45,52$, and 58 [2]. Therefore, the vaccine prevents most cases of HPV infection that can lead to serious health problems.

The HPV vaccine is made of reconstructed starry shields of the viruses, which cannot cause any harm to humans. Those shields are called virus-like particles (VLPs) because they look like the HPV virus but do not actually come from it. VLPs are created in laboratories using yeast cells (Figure 4). When a person receives the vaccine, the immune system reacts against the VLPs and remembers them. If the person gets infected by HPV later, the immune system will remember the starry shield of the virus and immediately fight to eliminate the virus from the body.

Girls and boys should be vaccinated against HPV between 9 and 15 years old. Why so early? It is important that you get your first HPV vaccine before you get intimate with somebody you like, because the virus is easily transmitted from one person to another. The sooner you get vaccinated, the fewer shots you need: between 9 and 14 years old, you only receive two shots, whereas if you are between 15 and 45 years old, you need three shots to be protected. The pinch of the shot is worth it, do not you think? Although the vaccine is very safe and effective, you might experience some mild side effects, such as a sore spot, swelling, and redness where the shot was given. Headaches and nausea can also occur, but less frequently.

\section{TESTING FOR HPV INFECTION}

HPV types not included in the vaccine can still cause infections in vaccinated people. Also, if people are infected before they get 
vaccinated, the virus can stay dormant in the body and develop into an infection later on. Therefore, it is important to regularly check for potential HPV infections.

Girls and women can be checked for HPV infection during a visit to the gynecologist, which is a type of doctor specializing in the health status of a woman's reproductive organs. The Pap test is used to check for changes in cervical cells. It is named after Dr. George Papanicolaou, the Greek physician who developed the test. The gynecologist uses a swab to lightly brush over the tissue of the cervix, to collect a sample of cells. These cells are then analyzed under a microscope to see whether they look healthy or abnormal. If cells have a strange appearance, it means that they might be infected by HPV and could potentially lead to a cancer. Through the Pap test, we can detect at least 8 out of 10 girls who are infected by HPV, and help them so they do not develop cancer nor spread the infection. HPV cannot be cured, but if a doctor detects the infection early enough, he can remove the infected tissue of the cervix. Because some types of HPV can hide and re-appear later, it is important that girls get the Pap test every 3 years.

Boys usually get tested when something strange appears on their genitals or if they find out their partner is infected. There is no Pap test for boys, but HPV can be detected using a laboratory technique that looks for the DNA of the HPV virus. When a wart is observed on the genitals of a girl or a boy, the doctor can collect the wart cells, which can then be tested in the lab to see if they contain HPV.

\section{WHAT DID I LEARN? VACCINATION TO PROTECT MYSELF AND OTHERS!}

HPV is very common. It is considered to be the most common sexually transmitted disease and men are equally infected than women. In most cases, infected people clear the virus from their bodies, but sometimes the immune system is not strong enough to fight it. Hence, some people develop serious health problem, such as cancer. Currently, no cure exist to get rid of this viral enemy, but we can protect ourselves with a vaccine.

The more people are vaccinated, the lower the risk of HPV infection will be. Spread the news to your friends, classmates, and family to create a chain of solidarity against HPV and decrease the transmission of the virus. Widespread immunization against HPV could reduce, and eventually even eliminate, cervical cancers and other diseases caused by HPV worldwide. 


\section{REFERENCES}

1. Song, D., Li, H., Li, H., and Dai, J. 2015. Effect of human papillomavirus infection on the immune system and its role in the course of cervical cancer. Oncol. Lett. 10:600-6. doi: 10.3892/ol.2015.3295

2. Garbuglia, A. R., Lapa, D., Sias, C., Capobianchi, M. R., and Del Porto, P. 2020. The use of both therapeutic and prophylactic vaccines in the therapy of papillomavirus disease. Front. Immunol. 11:188. doi: 10.3389/fimmu.2020.00188

3. Mammas, I. N., and Spandidos, D. A. 2017. Paediatric virology as a new educational initiative: an interview with nobelist professor of virology harald zur hausen. Exp. Ther. Med. 14:3329-31. doi: 10.3892/etm.2017.5006

SUBMITTED: 01 May 2020; ACCEPTED: 04 December 2020; PUBLISHED ONLINE: 15 January 2021.

EDITED BY: Michel Goldman, Institute for Interdisciplinary Innovation in healthcare (I3h), Belgium

CITATION: Neunez M, Nasif S, Smeesters PR and Stevens H (2021) Human Papillomavirus Is Dangerous-But a Vaccine Can Save You! Front. Young Minds 8:558213. doi: 10.3389/frym.2020.558213

CONFLICT OF INTEREST: The authors declare that the research was conducted in the absence of any commercial or financial relationships that could be construed as a potential conflict of interest.

COPYRIGHT @ 2021 Neunez, Nasif, Smeesters and Stevens. This is an open-access article distributed under the terms of the Creative Commons Attribution License (CC BY). The use, distribution or reproduction in other forums is permitted, provided the original author(s) and the copyright owner(s) are credited and that the original publication in this journal is cited, in accordance with accepted academic practice. No use, distribution or reproduction is permitted which does not comply with these terms.

\section{YOUNG REVIEWERS}

\section{A. Y. JACKSON S.S. (TORONTO DISTRICT SCHOOL BOARD), AGES: 13-15}

A. Y. Jackson Science Club promotes fun and challenging science initiatives through monthly events.

\section{AUTHORS}

\section{MARIE NEUNEZ}

Marie Neunez, Ir, is a Ph.D. student at the Faculty of Medicine and a Master student in medicine at the Université Libre de Bruxelles (ULB). Previously she was a part-time research assistant for 3 years at the Institute for Interdisciplinary Innovation in healthcare (I3h). She was a Clinical Research Coordinator for 2 years in the 

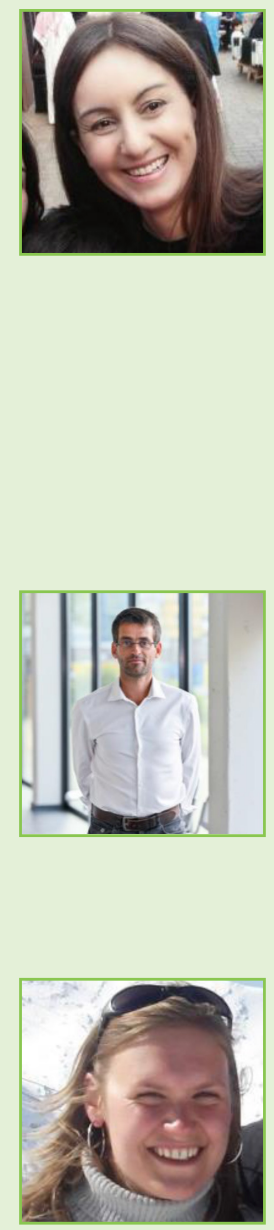

departments of Nuclear Medicine \& Radiotherapy at the Institut Jules Bordet (IJB). She also performed a 5-months internship at BASF SE (Mannheim, Germany) in the Human Health \& Nutrition department. Marie holds a Bachelor's degree in medicine (ULB, Belgium), a M.Sc. degree in bioengineering with a specialization in Science, Technology and Quality of Food (UCL, Belgium), a Post-graduate degree in Management (ICHEC Business Management School, Belgium), and a certificate in Clinical Studies (Cefochim, Belgium). *mneunez@i3health.eu

\section{SUSAN NASIF}

Susan Nasif, Founder of Cimaza Science for Public Health Education and Science/Medical Communication, uses science and art to spread awareness on science-information deficits and vaccines myths. Susan's company uses the scientific method to find the most effective form and languages to appeal to different audiences. Combining her talent and research Susan's comics are fun and informative in many EU languages and in Arabic. She has received three global recognitions, winning the 2015 Science Hero Award, 2017 Innovation in Science Literacy Award, and 2018 Europe (Silver) Vaccines Communication Challenge Award. Susan's Linkedln url is: https://www.linkedin.com/in/ susannasifphd/.

\section{PIERRE R. SMEESTERS}

Pierre Smeesters is a pediatrician working as the head of the pediatric department from the Academic Children's Hospital Queen Fabiola at the Free University of Brussels (ULB) in Belgium. He is also leading a research group in Microbiology and Infectious Disease at the Free University of Brussels. His research interests include translational research in Strep A, vaccination, new diagnostic tests, and societal issues related to childhood.

\section{HILDE STEVENS}

I am an Associate Professor at the Université Libre de Bruxelles. My research focuses on how people with various cultures and ways of working (e.g., academics or people in the pharmaceutical industry) could optimally collaborate to bring inventions from the lab to the patient much faster, and how patients in low- and middle-income countries also could get access to innovative therapies. I love telling stories to my children about bad bugs and how to fight them, and then we make paintings about it! 